\title{
Analysis of Representativeness of the Paramo Ecosystem in the Conservation Modalities of the Chimborazo Province
}

\section{Análisis de Representatividad del Ecosistema Páramo en las Modalidades de Conservación de la Provincia de Chimborazo}

\author{
P, Lozano Rodríguez, A, Armas Armas, E, Molina Bustamante, and V, Flores \\ Cantos
}

VII International Congress of

Science, Technology,

Entrepreneurship and

Innovation (SECTEI 2020)

Corresponding Author:

P, Lozano Rodríguez

plozano@espoch.edu.ec

Published: 26 August 2021

Production and Hosting by

Knowledge E

(c) P, Lozano Rodríguez et al. This article is distributed under the terms of the Creative Commons Attribution License, which permits unrestricted use and redistribution provided that the original author and source are credited.

\section{Abstract}

The paramo ecosystem has ecological, social, cultural and economic importance due to the ecosystemic services of supply, regulation, support and culture that it provides to local populations for their well-being, therefore, it needs to be conserved and managed from an ecosystemic approach. The objective of this work is to analyze the conservation modalities that protect the paramo ecosystem in the Chimborazo province. To conduct the research, a systematic review of 30 cartographic sources was carried out, and documentary information on 7 variables of the paramo ecosystem was made, provided by institutions in charge of managing the province's natural resources, and found in articles consulted in scientific and academic databases. Additionally, gray literature has been included through manual search. The results indicate that the Chimborazo province has $17.93 \%$ of its extension under conservation modality, through 121 protected natural spaces, distributed in 3 modalities. The paramo ecosystem represents $36.40 \%$ of the province's size, and is made up of 9 vegetation formations. $15.10 \%$ of this ecosystem are under conservation modality, however, only 3 of the 121 spaces have planning documents for the management of these spaces.

Keywords: paramo ecosystem, ecosystem services, conservation modalities.

\section{Resumen}

El ecosistema páramo tiene importancia ecológica, social, cultural y económica por los servicios ecosistémicos de abastecimiento, regulación, soporte y culturales que suministra a las poblaciones locales para su bienestar, por tanto, requiere ser conservado y manejado desde un enfoque ecosistémico. El objetivo de este trabajo es analizar las modalidades de conservación que protegen el ecosistema páramo en la provincia de Chimborazo. Para llevar a cabo la investigación se realizó una revisión sistémica de 30 fuentes de información cartográfica y documental sobre 7 variables del ecosistema páramo, facilitadas por instituciones encargadas del manejo de los recursos naturales de la provincia, y encontradas en artículos consultados en bases de datos científicas y académicas, adicionalmente se ha incluido literatura gris mediante la búsqueda manual. Los resultados indican que la provincia de Chimborazo tiene 17,93\% de su extensión bajo modalidad de conservación, a través de 121 espacios naturales protegidos, distribuidos en 3 modalidades. El ecosistema páramo representa el 36,40\% de la extensión de 
la provincia y está conformada por 9 formaciones vegetales. El 15,10\% de éste ecosistema se encuentran bajo modalidad de conservación, sin embargo, únicamente 3 de los 121 espacios poseen documentos para el manejo de estos espacios.

Palabras Clave: ecosistema páramo, servicios ecosistémicos, modalidades de conservación.

\section{Introducción}

La diversidad biológica puede ser interpretada como la variedad de organismos, ecosistemas o paisajes que existen en una región dada; de tal forma que, es un concepto jerárquico que integra varias escalas de análisis, desde los ecosistemas y los paisajes hasta las especies y los genes en un contexto de tiempo y espacio [1]. Dentro de estas escalas se encuentran los páramos, que en el contexto de los Andes, es el más reciente de los ecosistemas constituidos, puesto que su formación y colonización a las condiciones de la parte andina no tiene más de tres millones de años, es decir, un tiempo relativamente corto respecto a las demás formaciones vegetales del continente [2].

Construyendo una definición, los páramos son ecosistemas neotropicales de alta montaña [3], conformados por múltiples áreas abiertas y complejas, las cuales se encuentran localizadas en las regiones andinas a altitudes que oscilan entre 2.800 y 4.700 msnm [4, 5]. Estos ecosistemas se caracterizan por presentar mayor irradiación solar [6] debido a la presencia de factores como la altitud, la precipitación, la alta humedad relativa $\left(60 \%\right.$ ante $30 \%$ ) y las temperaturas que oscilan entre -4 y $6^{\circ} \mathrm{C}$, por cuanto, el clima de los páramos es frío y va acompañado de súbita niebla y llovizna, además el tapiz vegetal que lo constituye es tupido [7]. En toda su extensión en el Neotrópico, los páramos cubren alrededor del $2 \%$ (alrededor de $35.000 \mathrm{~km}^{2}$ ) de la superficie de los países, encontrándose principalmente en Colombia, Venezuela, Ecuador y el norte de Perú [8].

Dentro de Ecuador el páramo cubre alrededor de 1'250.000 ha, es decir, aproximadamente un 7\% del territorio, y se extiende desde el límite norte con Colombia hasta la frontera sur con Perú. En términos numéricos, este ecosistema a través del corredor andino recorre $600 \mathrm{~km}$ de longitud, y aproximadamente $180 \mathrm{~km}$ de ancho por medio de la columna vertebral de los Andes [9]. Con este antecedente se puede afirmar que el Ecuador es el país que más páramo tiene con respecto a su extensión total [10], desafortunadamente, menos del $40 \%$ de este ecosistema está protegido formalmente [11].

Los páramos han sido reconocidos como una de las áreas más importantes a nivel mundial, constituyéndose como uno de los puntos claves globales 'hot spots' [12], 
debido a su alta variabilidad y tasas de endemismo [13], ya que a lo largo del gradiente montañoso que se extiende sobre este ecosistema se encuentran aproximadamente el $6,7 \%$ de las plantas endémicas y el 5,7\% de las especies de vertebrados del mundo [14].

El páramo al ser un ecosistema de altura inmerso en un sistema socio- ecológico multi-escalar conocido como la alta montaña ecuatorial, coexiste con otros sistemas y debido a la simbiosis de múltiples atributos biofísicos, los páramos generan una gran variedad de servicios ecosistémicos [15], los mismos que se describen como los bienes generados por la naturaleza y de los cuales se beneficia la sociedad [16]; entre ellos se encuentran la materia prima, fibra (aprovisionamiento), regulación hídrica, regulación del clima, almacenamiento de carbono (regulación) [17, 18], formación del suelo (soporte), recreativos y estéticos (culturales) [19].

Así por ejemplo la importancia de los páramos como fuente de agua para la población, reside en su historia y su clima; durante las glaciaciones, que se presentaron durante los últimos 2,5 millones de años, los glaciares se extendieron cubriendo todas las actuales áreas de páramo, bajando hasta unos $3.000 \mathrm{~m}$ de altitud [20].

Desafortunadamente, la capacidad de los ecosistemas para suministrar servicios está disminuyendo [21] y los páramos no son ajenos a esta realidad; el excesivo uso de pesticidas, la quema, la deforestación, se han convertido en una seria amenaza antrópica en estas regiones [22]. Estos ecosistemas están especialmente sujetos a sobrepastoreo y cultivo, lo que conduce a la reducción de la biodiversidad [23] y la pérdida de la estructura, composición y funcionalidad. Específicamente en América del Sur, los páramos han venido experimentando una transición a actividades agrícolas y pecuarias como el cultivo de papa y el pastoreo de ganado, lo cual contribuye a la pérdida de nutrientes del suelo y la erosión del suelo [24].

En el Ecuador los páramos se distribuyen en un callejón casi ininterrumpido sobre la línea de bosque de las cordilleras oriental y occidental en los pisos montano alto superior y subnival y excepcionalmente en el piso montano alto, por cuanto en el sur del país se encuentra desde los 2800 msnm. La provincia de Chimborazo posee más de 236.000 hectáreas que corresponde al $36,9 \%$ de la superficie de la provincia, y el 17,7\% del total de superficie de páramo a nivel nacional [25].

En Chimborazo este ecosistema está conformado por las siguientes formaciones: Bosque siempreverde del Páramo, Herbazal húmedo montano alto superior del Páramo, Herbazal inundable del Páramo, Herbazal y Arbustal siempreverde subnival del Páramo, Herbazal húmedo subnival del Páramo, Herbazal ultrahúmedo subnival del Páramo, Bosque y Arbustal semideciduo del norte de los Valles [26] y se encuentra bajo modalidad de conservación [27] por ser un ecosistema representativo.

Adicionalmente, el páramo en la provincia de Chimborazo forma paisajes con importancia ecológica, socio-cultural y económica que permiten el desarrollo de múltiples 
actividades de generación de conocimiento, recreación y esparcimiento, debido a la presencia de la Cordillera de los.

Andes, que origina una variedad de climas, precipitaciones y pisos altitudinales en cortas distancias, así como también, una distribución espacial variable, debido a su orografía y a factores ambientales que condiciona las misma.

A pesar del grado de importancia que representa el páramo, este ecosistema muestra un alto grado de intervención, ya que fueron considerados tierras improductivas, hostiles y con poca oferta [28] y aunque en los últimos años esta situación ha cambiado, debido a que se ha incrementado el interés y reconocimiento de la importancia que tienen estos ecosistemas para el bienestar de la población [29, 30], gracias a los resultados de estudios impulsados desde la academia [31, 32].

En este contexto, es imperante la conservación del ecosistema páramo, para lo cual se debe realizar un proceso de planificación sistemática identificando de forma participativa las metas de conservación [33]. Este proceso tiene como primer paso la identificación de vacíos y prioridades de conservación, el cual es un análisis territorialespacial crítico de los esfuerzos e instrumentos que se han implementado para proteger el ecosistema páramo, y tiene como propósito identificar áreas prioritarias para la conservación, basado en el estado actual de la biodiversidad, la representatividad del sistema de conservación y variables ambientales [34].

En el marco de éste proceso, el presente estudio planteó la siguiente pregunta de investigación: ¿Qué modalidades de conservación protegen el ecosistema páramo en la provincia de Chimborazo? Para resolver esta pregunta se formularon los siguientes objetivos: (a) caracterizar las áreas y modalidades con propósitos de conservación en la provincia, (b) Analizar la extensión y las formaciones vegetales que conforman al ecosistema páramo en la provincia y (c) Determinar la representatividad del ecosistema páramo en las modalidades de conservación de la provincia.

El propósito de este estudio fue analizar las modalidades de conservación que protegen el ecosistema páramo en la provincia de Chimborazo, para que a su vez permitan impulsar acciones de conservación del referido ecosistema.

\section{Metodología}

\section{1. Área de Estudio}

El presente estudio se realizó en la jurisdicción de la provincia de Chimborazo, cuyas coordenadas son: latitud $1^{\circ} 40^{\prime} 00^{\prime \prime} \mathrm{S}$, longitud $78^{\circ} 39^{\prime} 00^{\prime \prime} \mathrm{O}$. El rango altitudinal de la provincia de Chimborazo va desde los 135 msnm hasta los 6268 msnm [35] (Figura 1). 


\section{UBICACIÓN GEOGRÁFICA DE LA PROVINCIA DE CHIMBORAZO}
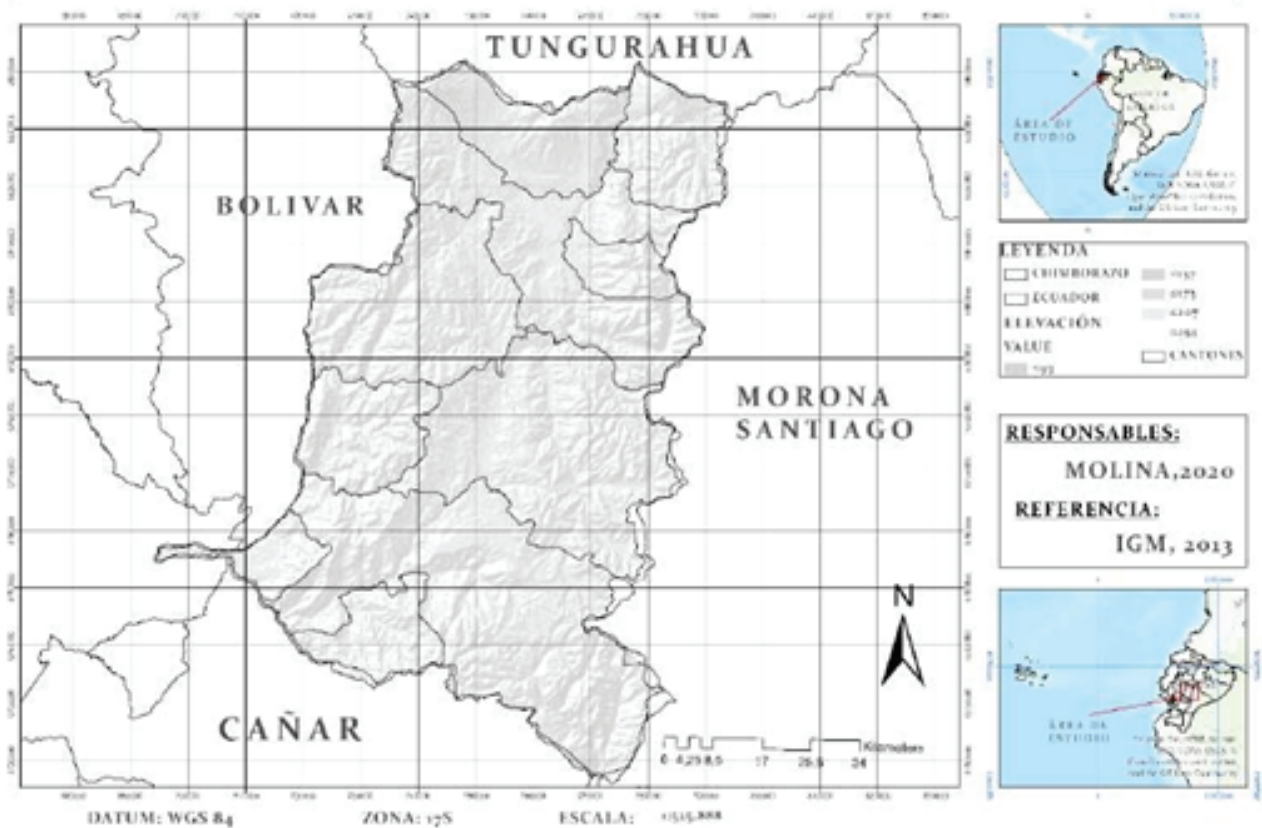

RESPONSABLES;

MOLINA,2020

REFERENCLA:

IGM, 2013

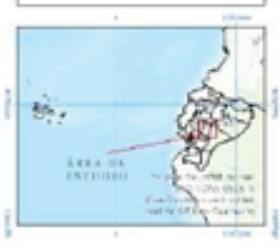

Figure 1

Mapa de área de estudio.

\subsection{Métodos}

El presente estudio es de tipo exploratorio y descriptivo, y para su realización se aplicó el método de investigación documental, para lo cual se realizó una revisión sistémica de 30 fuentes de información cartográfica y documental sobre 7 variables del ecosistema páramo, facilitadas por instituciones oficiales encargadas del manejo de los recursos naturales de la provincia, y encontradas en artículos científicos y académicos consultados en las bases de datos Science Direct y Scielo, adicionalmente se incluyó literatura gris mediante la búsqueda manual. A continuación, se presenta las variables y los criterios para la selección y revisión de información:

El procedimiento para el tratamiento, revisión y análisis de la información recopilada se describe por cada objetivo:

\subsection{Caracterización de las áreas y modalidades con propósitos de conservación en la provincia}

Se caracterizaron las distintas modalidades de cada una de las áreas protegidas de la provincia de Chimborazo tomando en cuenta los siguientes criterios: localización, clima, hábitat, aspectos socio-económicos, declaración, gobernanza, manejo, plan de 


\section{Table 1}

Variables y criterios para la selección y revisión de información.

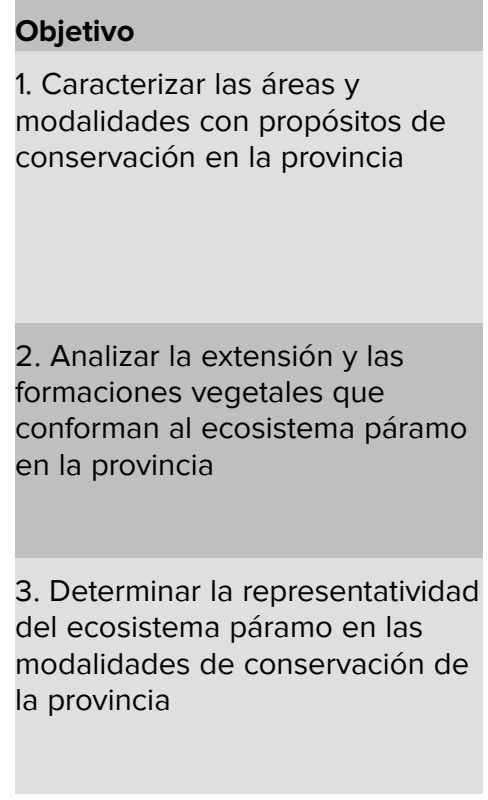

Variable
Áreas con propósito de
conservación en la provincia
Tipología de modalidades de
conservación en la provincia
Formaciones vegetales del
ecosistema páramo en la
provincia
Extensión del ecosistema
páramo en la provincia
Extensión de páramo bajo
modalidad de conservación
Áreas de páramo con modalidad
de conservación que cuentan con
instrumentos de manejo

Criterio
Localización
Clima
Hábitat
Declaración
Gobernanza
Tipo de modalidad
Manejo
Extensión
Altitud
Clima
Fisionomía
Especies de flora
Especies de fauna
Extensión del páramo
Modalidad de conservación
Áreas con instrumentos de
manejo
Modalidades de conservación
con páramo

inversión (PSB). Posteriormente se realizó el procesamiento y análisis de información cartográfica base correspondiente a ecosistemas y modalidades de conservación obtenida del Ministerio del Ambiente (2015), SIG Tierras (2015) e Instituto Geográfico Militar $(2013,2015)$. A la vez se generó información carente (bosques y vegetación protectora) mediante el software ArcGis 10.3 mismo que permitió conectar físicamente los atributos y relacionarlos con cardinalidad

1 a 1 o a muchos campos con el mismo tipo de datos mediante la codificación y la herramienta 'Join' [36].

\subsection{Análisis de la extensión y las formaciones vegetales que con- forman el ecosistema de páramo en la provincia}

Mediante el método de análisis y manejo de información y la técnica de discriminación de información se identificaron: (a) formaciones vegetales que pertenecen al ecosistema páramo a través de los criterios de altitud, clima y fisionomía; (b) zonas de alto valor ecológico a través de los criterios funcionales, especies de flora y fauna. Posteriormente a través el software ArcGis 10.3 se descartó la información de las formaciones vegetales que no pertenecen al páramo de la tabla de atributos de las bases de datos, para finalmente ser analizadas y cuantificadas el total de áreas correspondiente al ecosistema páramo. 


\subsection{Representatividad del ecosistema páramo en las modalidades de conservación de la provincia}

Se realizó un análisis de superposición con la herramienta de análisis ‘Clip' del software ArcGis 10.3 que sirve para extraer o hacer cortes según el área de interés (Figura 2). Para el análisis de la representatividad del ecosistema páramo en las modalidades de conservación de la provincia de Chimborazo se utilizaron los siguientes criterios: (a) modalidad de conservación en áreas con propósitos de conservación, (b) extensión de las formaciones vegetales y modalidades de conservación con respecto a la provincia de Chimborazo y al Ecuador continental, y (c) número de formaciones vegetales pertenecientes al ecosistema páramo que se encuentran dentro de las modalidades de conservación. Finalmente se elaboraron mapas temáticos para lo cual se procedió a dividir los espacios que poseen páramo por modalidad de conservación.

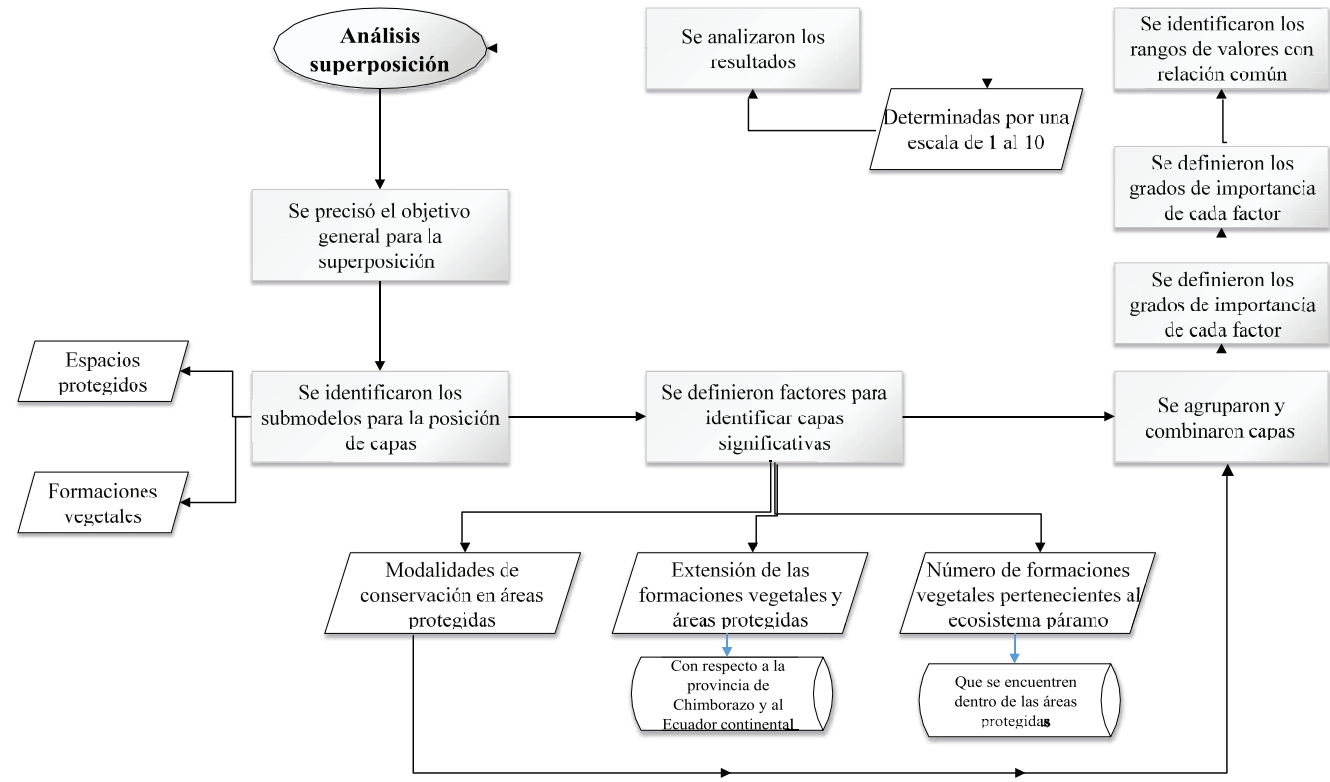

Figure 2

Análisis de superposición para determinar la representatividad del ecosistema páramo.

\section{Resultados y Discusión}

\subsection{Caracterización de las áreas y modalidades con propósitos de conservación en la provincia}

Las áreas con propósitos de conservación de la provincia de Chimborazo pertenecen al SNAP, Bosques Protectores, y al Programa Socio Bosque, las mimas que se detallan a continuación: 


\subsubsection{El Patrimonio de Áreas Naturales del Estado (PANE)}

En la provincia de Chimborazo se encuentran dos áreas protegidas que son: la primera, el Parque Nacional Sangay, el cual se creó mediante Acuerdo Ministerial 190 del 16 de junio de 1975, publicado en el Registro Oficial 840 del 7 de julio del mismo año, se estableció legalmente como Reserva Ecológica Sangay. Para 1976 se realiza el Estudio de Alternativas de Manejo del Área Circundante al Volcán Sangay, dicho estudio recomendó considerar el área como Parque Nacional, sin embargo los límites definitivos del PNS se establecieron el 26 de Julio de 1979, fecha en la que oficialmente recibe la categoría de Parque Nacional mediante Acuerdo Interministerial 0322 publicado en el Registro Oficial 69 del 20 de Noviembre de 1979 [37], además esta área protegida cuenta con un documento de planificación para el manejo realizado en el año 1998 denominado 'Plan de manejo estratégico del Parque Nacional Sangay'.

Esta área protegida se ubica en las provincias de Tungurahua, Chimborazo, Cañar y Morona Santiago, limita al norte con la provincia de Tungurahua, al sur con la provincia de Cañar, al este con las provincias de Pastaza y Morona Santiago y al oeste con la provincia de Chimborazo. Esta área posee una extensión de 502.229,37 ha; su altitud va desde los 1000 msnm hasta los 5230 msnm, presenta una precipitación anual de 500-4000 mm, y una humedad relativa del 94\%.

En relación a la fauna más representativa están los osos de anteojos (Tremarctos ornatus), Tapir de montaña (Tapirus pinchaque), Jaguar de la Amazonia (Panthera onca), Cóndor andino (Vultur gryphus), Nutria común (Lontra longicaudis), Tigrillo chico (Leopardus tigrinus), Gato andino (Leopardus pajeros), Puerco espín de cola corta (Coendou rufescens), Puma (Puma concolor), Lobo de paramo (Lycalopex culpaeus), Ciervo enano (Pudu mephistophiles), Cuy silvestre de Patzelt (Cavia patzelti), Ratón marsupial del Sangay (Caenoloestes sangay), Venado de cola blanca (Odoncoileus virginianus); mientras que la flora más representativa es Polylepis (Polylepis incana), Achupalla (Puya sp), Polylepis (Polylepis reticulata), Quishuar (Buddleja incana), Paja (Calamagrostis intermedia), Chuquirahua (Chuquiraga jussieui), Pumamaqui (Oreopanax ecuadorensis), Piquil (Gynoxys sp), Orquídea (Lepanthes dalessandroi), Orquídea (Masdevallia rosea), Orquídea (Sobralia rosea), Orquídea (Cyrtochulum cuencanum).

Según el Plan estratégico de octubre de 1998 los ecosistemas presentes en esta área son los siguientes: Bosque siempreverde montano alto del Norte de la Cordillera Oriental de los Andes, Arbustal siempreverde y Herbazal del Páramo, Herbazal del Páramo, Bosque siempreverde del Páramo, Bosque siempreverde montano del Norte de la Cordillera Oriental de los Andes, Bosque siempreverde piemontano del Norte de la Cordillera Oriental de los Andes, Bosque siempreverde montano bajo del Norte de la Cordillera Oriental de los Andes, Herbazal y Arbustal siempreverde subnival del Páramo, 
Herbazal húmedo montano alto superior del Páramo, Bosque inundable de la llanura aluvial de los ríos de origen andino y de Cordilleras Amazónicas, Arbustal siempreverde ripario de la Cordillera Oriental de los Andes, Bosque siempreverde montano del Sur de la Cordillera Oriental de los Andes, Bosque siempreverde montano bajo del Sur de la Cordillera Oriental de los Andes, Herbazal lacustre montano bajo del Sur de la Cordillera Oriental de los Andes, Bosque siempreverde montano alto del Sur de la Cordillera Oriental de los Andes, Herbazal ultra húmedo subnival del Páramo, Herbazal inundable del Páramo, Bosque siempreverde piemontano del Sur de la Cordillera Oriental de los Andes, Arbustal siempreverde montano del norte de los Andes. Adicionalmente el sistema hidrográfico del PNS comprende 11 subcuencas, 69 subcuencas primarias, 54 subcuencas secundarias y 8 terciarias que pertenecen a cuatro grandes subsistemas fluviales de los ríos Pastaza, Santiago, Cañar y Chimbo que representan el 43.25\%, $51.8 \%, 4.51 \%$ y $0.44 \%$ de la superficie total del parque $\left(5.177,25 \mathrm{~km}^{2}\right)$, respectivamente.

La segunda área es, la Reserva de Producción de Fauna Chimborazo, esta se creó mediante Acuerdo Ministerial No. 437 del 26 de octubre de 1987, publicado en el Registro Oficial No. 806 del 9 de noviembre del mismo año, además cuenta con un documento de planificación para el manejo creado en el año 1992. Se encuentra en la Ecorregión Páramo de los Andes del Norte que se extiende a través de Colombia y Ecuador desde los 2.900 hasta los 3.650, y en el límite superior incluye los pisos subnivales en donde se aprecian formas de vida [38]. Geográficamente se localiza en las provincias de Bolívar, Chimborazo y Tungurahua, limita al norte con la provincia de Tungurahua, al sur la provincia de Chimborazo, al este la provincia de Tungurahua y al oeste la provincia de Bolívar y posee una extensión de 52663.27 ha. Esta área posee una altitud que va desde los 3.800 hasta los $6.268 \mathrm{msnm}$, una precipitación anual de 250 y 4000 mm, y una humedad relativa del 89\%. En relación a la fauna representativa el grupo más importante es el de los camélidos con llamas (Lama glama) y vicuñas (Vicugna vicugna); mientras que las principales maderas nativas utilizadas para combustible son piquil (Gynoxys sp.), pichana (Brachyotum ledifolium), chilca (Baccharis latifolia), árbol de papel (Polylepis reticulata). En ciertas quebradas, zonas más húmedas y protegidas del viento, se pueden encontrar poblaciones de árboles de papel (Polylepis reticulata) y quishuares (Buddleja incana), con los que se realiza reforestación en el área.

El Patrimonio de Áreas Naturales del Estado suministra servicios ecosistémicos como: (a) agua de los diferentes Ríos: el sistema hidrográfico del PNS comprende 11 subcuencas, 69 subcuencas primarias, 54 subcuencas secundarias y 8 terciarias que pertenecen a cuatro grandes subsistemas fluviales de los ríos Pastaza, Santiago, Cañar y Chimbo; mientras que en la Reserva el Chimborazo y el Carihuairazo constituyen gigantescos reservorios de agua en estado sólido, (b) carbono y otros nutrientes, y (c) finalmente los valores de conservación del PANE son principalmente el Páramo, 
los sistemas hídricos, el Bosque Andino y Húmedo, la Vicuña (Vicugna vicugna) y el Cóndor Andino (Vultur gryphus).

\subsubsection{Los bosques protectores}

Los Bosques Protectores de la Provincia de Chimborazo se encuentran ubicados en los cantones: Colta, Cumandá, Riobamba y Alausí, limitan con las provincias de Bolívar y Guayas, con los cantones Riobamba, Chambo y con las parroquias de Calpi, La Calendaria, Juan de Velasco y Cañi y tienen una extensión que va desde 51 ha hasta 6.630 ha. Entre otras características presentan una altitud que va desde los 3600 a los 4100 msnm, una precipitación anual de 1064 mm.

La fauna representativa es: Curiquingue (Phalcoboenus carunculatus), Zorillo (Conepatus semistriatus), Conejo (Sylvilagus brasiliensis), Ratón campestre (Akodon latebricola), Colibrí estrella ecuatoriana (Oreotrochilus Chimborazo), Lagartija de páramo (Pholidobolus macbrydei). La flora representativa es: Geranio de páramo (Geranium sibbaldioides), Almohadilla (Plantago rigida), Paja de páramo (Calamagrostis effusa), Lysipomia (Lysipomia muscoides), Lachemilla (Lachemilla Orbiculata), Lengua de vaca (Rumex crispus), Sangre de toro (Rumex acetosella), Quishuar (Buddleja $s p$ ). Dentro de las actividades económicas que se realizan en estos espacios es el manejo de alpacas, los principales productos que se cultivan en los alrededores de la zona son: la papa, habas; las principales especies de animales que se encuentra en la zona son: bovinos, ovinos, camélidos sudamericanos.

\subsubsection{El Programa Socio-Bosque (PSB) individual y colectivo}

Estos se localizan en los cantones: Colta, Alausí, Penipe, Guamote, Chambo, Guano, Riobamba y Pallatanga. Estos limitan al norte con las parroquias: Cebadas, Sevilla, Cañi, Puela, Quimiag, Palmira, San Andrés; al sur con las parroquias: Achupallas, Matus, Pungalá, Juan de Velasco, Multitud, Villas la Unión y la Calendaria; al este con las parroquias: Palmira, El Altar, Juan de Velasco, Sibambe, Columbe y el Parque Nacional Sangay; y al oeste con las parroquias: San Antonio de Bayushig, Matus, Achupallas, Cañi, Guasuntos, Compud y Capsol, San Isidro de Patulu. Representan el 12,54\% de hectáreas del total de espacios protegidos de la provincia de Chimborazo, el 2,25\% de hectáreas del total de la provincia y el 0,05\% hectáreas del total del territorio del país. En el PSB Colectivo ingresaron el 38,89\% de los espacios naturales protegidos en el año 2012, mientras que el 27,78\% ingresaron en el año 2011, y el PSB Individual ingresó el 41,63\% en el año 2014 y el 16,50\% en el 2013, además, ninguno de los 112 espacios que cuenta el programa cuentan con documentos de planificación para el manejo, únicamente cuentan con documentos de creación. 
El Proyecto Socio-Bosque recibe incentivos anuales en el caso de los colectivos, van desde los 3024 hasta los 37.078,4 dólares y en el caso de los privados o individuales va desde los 133,8 hasta los 2293,9 dólares; estos incentivos son dedicados para la conservación del páramo con un número de hectáreas que van desde las 50 ha hasta las 2573,7 ha.

\subsubsection{Análisis}

La provincia de Chimborazo cuenta con 121 áreas protegidas distribuidas en 3 modalidades de conservación como el PANE, Bosques Protectores y el Programa Socio Bosque (PSB) Colectivo e individual (Tabla 2).

La primera, el PANE, que para Chimborazo integra la Reserva de Producción de Fauna Chimborazo y el Parque Nacional Sangay, ya que las áreas protegidas son una forma esencial e irremplazable para proteger ecosistemas, biodiversidad [39], y servicios ecosistémicos, los mismos que son claves para el bienestar humano [40]; en este sentido la Reserva de Producción de Fauna Chimborazo y el Parque Nacional Sangay representan el $79,32 \%$ de hectáreas del total de los espacios naturales protegidos de la provincia, el $14,22 \%$ de hectáreas totales de la provincia de Chimborazo y el 0,37\% de hectáreas totales del territorio nacional. La fauna representativa dentro del sistema PANE son las especies de llamas, Vicuñas (Vicugna vicugna), Lobo de Páramo (Odocoileus virginianus), Cóndor Andino (Vultur gryphus), Venado de Cola Blanca (Odoncoileus virginianus), Oso de Anteojos (oso de anteojos) y Tapir de Montaña (Tapirus pinchaque). La flora representativa del mismo son las especies de Polylepis (Polylepis sp.), Piquil (Gynoxys sp), y Orquídeas (Cyrtochulum cuencanum). Los valores de conservación del PANE son principalmente el Páramo, los sistemas hídricos, el Bosque Andino y Húmedo, la Vicuña (Vicugna vicugna) y el Cóndor Andino (Vultur gryphus).

La segunda, los Bosques Protectores, los mismos que son formaciones vegetales, no aptas para la agricultura o la ganadería, y su función principal es la de conservar el agua, suelo, flora y la fauna silvestre [41]. En el Ecuador existen 202 BVP, de los cuales 169 se encuentran georeferenciados, los mismos que abarcan una superficie de 2’425.002,9 hectáreas, que representa el 9,72\% del territorio nacional.

Se localizan en áreas de topografía accidentada, en cabeceras de cuencas hidrográficas o en zonas que, por sus condiciones climáticas, edáficas e hídricas, no son aptas para la agricultura o la ganadería, sus funciones son las de conservar el agua, el suelo, la flora y la fauna silvestres. Dentro de la provincia representan el 8,15\% de hectáreas del total de los espacios naturales protegidos de la provincia de Chimborazo, el 1,46\% de hectáreas totales de la provincia y el 0,038\% de hectáreas del total del territorio nacional. Sin embargo 6 de los 7 Bosques Protectores de la provincia no cuentan con 
un instrumento técnico de manejo debido a que están en proceso de elaboración o no se han elaborado. La fauna representativa de dicho Bosque es la lagartija de páramo (Pholidobolus macbrydei), el Curiquingue (Phalcoboenus carunculatus) y el Colibrí Estrella (Oreotrochilus Chimborazo). En cuanto a la flora existen Almohadillas (Silene acaulis), Sangre de Toro (Ramphocelus carbo) y Geranio de Páramo (Geranium, sibbaldioides).

La tercera, el Programa Socio-Bosque Individual y Colectivo, el mismo que busca conservar áreas de bosques y paramos, consiste en la entrega de incentivos económicos a campesinos y comunidades indígenas que se comprometen voluntariamente a la conservación y protección de sus bosques nativos, páramos u otra vegetación nativa [42]. Aquí pueden participar propietarios individuales o de comunidades indígenas y campesinas del Ecuador que en su posesión mantengan tierras con cobertura boscosa nativa y en áreas prioritarias para la conservación a nivel nacional, las mismas que se enmarcan dentro de los siguientes criterios: áreas con alta amenaza de deforestación, áreas relevantes para la generación y conservación de servicios ambientales y áreas con altos niveles de pobreza [43].

\section{Table 2}

Análisis de áreas protegidas.

\begin{tabular}{l|l|l|l|l|}
$\begin{array}{l}\text { Modalidades de } \\
\text { conservación }\end{array}$ & ENP & $\begin{array}{l}\text { Modalidades de } \\
\text { conservación (ha) } \\
\text { PANE }\end{array}$ & $\begin{array}{l}\text { Provincia de } \\
\text { Chimborazo (ha) }\end{array}$ & $\begin{array}{l}\text { \% Provincia de } \\
\text { Chimborazo }\end{array}$ \\
\hline $\begin{array}{l}\text { Bosques } \\
\text { protectores }\end{array}$ & $\begin{array}{l}\text { 121 áreas } \\
\text { protegidas }\end{array}$ & $\begin{array}{l}9.455,91 \\
14,22 \%\end{array}$ \\
\hline $\begin{array}{l}\text { PSB Colectivo e } \\
\text { Individual }\end{array}$ & $14.612,03$ & $649.969,10$ & $1,46 \%$ \\
\hline $\begin{array}{l}\text { Total ENP } \\
\text { 116.562,30 ha }\end{array}$ & & & $\begin{array}{l}\text { TOTAL \% provincia } \\
\text { de Chimborazo }\end{array}$ & $\mathbf{1 7 , 9 3 \%}$ \\
\hline
\end{tabular}

En conclusión, los espacios naturales protegidos se encuentran en todos los cantones de la provincia excepto en el cantón Chunchi. Según la modalidad de conservación, se encuentran en los siguientes cantones: (a) modalidad PANE en Riobamba, Guano, Penipe, Chambo, Guamote y Alausí, (b) modalidad Bosques Protectores en Riobamba, Chambo, Pallatanga, Alausí y Cumandá y finalmente (c) modalidad Programa Socio-Bosque; (1) Colectivo en: Guano, Riobamba, Chambo, Colta, Pallatanga, Guamote y Alausí; (2) Individual en casi todos los cantones, excepto Chambo, Cumandá y Chunchi (Figura 3). 


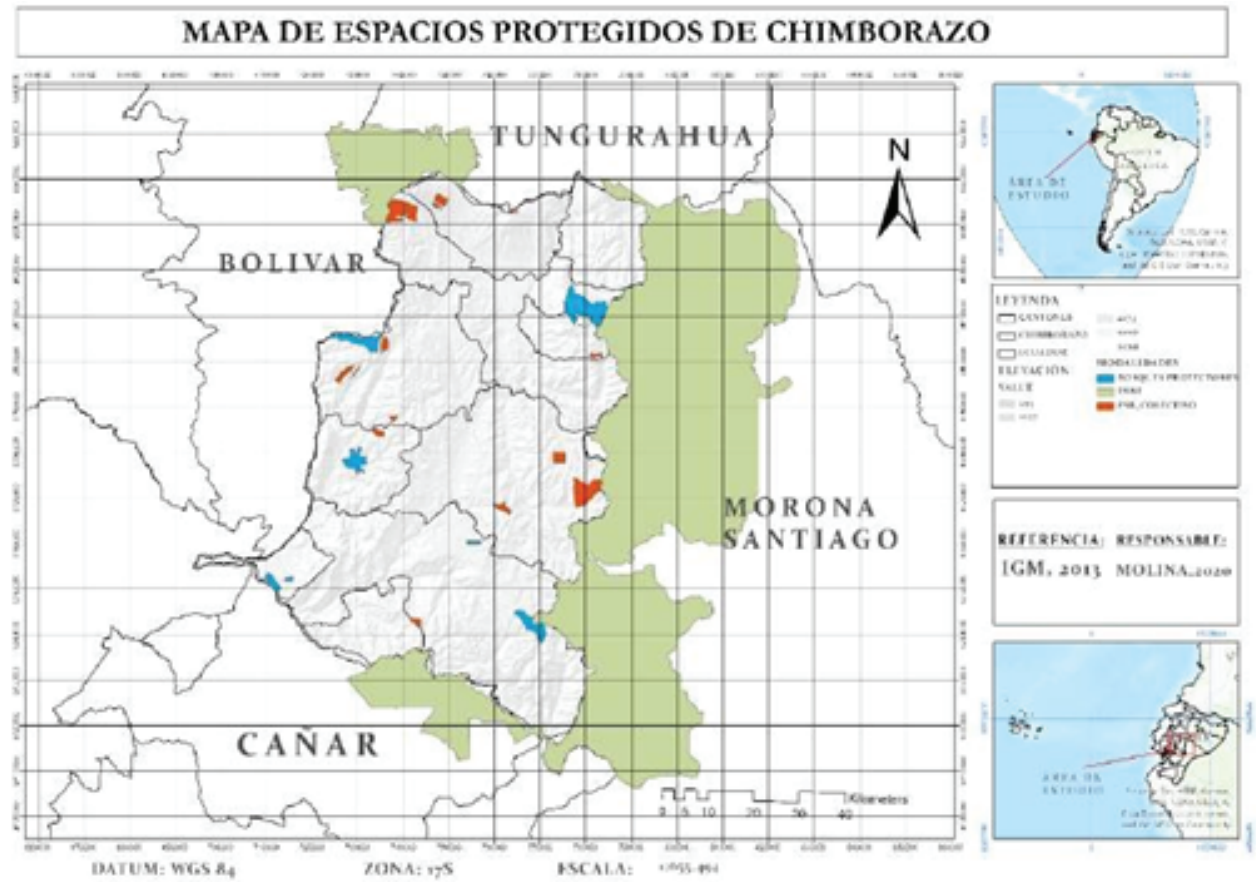

Figure 3

Espacios protegidos de Chimborazo.

\subsubsection{Análisis de la extensión y las formaciones vegetales que confor- man el ecosistema de páramo en la provincia}

La provincia de Chimborazo cuenta con 17 formaciones vegetales de las 91 que presenta el Ecuador continental, de las cuales 9 de ellas fueron identificadas como formaciones vegetales pertenecientes al ecosistema Páramo (Tabla 3). Estas formaciones muestran una temperatura que va desde $1^{\circ} \mathrm{C}$ hasta los $7^{\circ} \mathrm{C}$ y altitudes que van desde los 3100 a los 4.900 m.s.n.m., todos pertenecientes a la Cordillera Occidental de los Andes.

La fisionomía característica de estas formaciones vegetales son las vegetaciones herbazales y arbustivas, con árboles de hasta 15 metros de altura que generalmente crecen ramificados por las características climáticas, la mayoría con un sotobosque rico en vegetación herbácea. Las especies más representativas de estas formaciones vegetales son los géneros Calamagrostis, Afrostis, Stipa y Plantago, con especies como las plantas briofitas, gramíneas y epífitas.

Así la formación vegetal: (a) Arbustal Siempreverde y Herbazal del Páramo presenta principalmente plantas fanerógamas; (b) Bosque Siempreverde del Páramo crecen aislados de la vegetación arbustiva y herbácea, generalmente en sitios donde haya menor cantidad de viento cubierto principalmente de plantas briofitas, líquenes y epifitas; (c) Bosque Siempreverde Montano Alto de la Cordillera Occidental de los Andes presenta un sotobosque denso de vegetación herbácea como las plantas epífitas (orquídeas, bromelias, helechos) y briofitas (musgo); (d) Herbazal de Páramo tiene suelos 
Table 3

Formaciones vegetales del ecosistema páramo.

Formaciones vegetales
Arbustal siempreverde y
herbazal del Páramo
Bosque siempreverde del
Páramo
Bosque siempreverde
montano alto de la
Cordillera Occidental de los
Andes
Herbazal del Páramo
Páramo
Herbazal ultrahúmedo
Hubnival del Páramo
Herbazal y Arbustal
alto superior del Páramo
Herbazal húmedo subnival
Páramo

\begin{tabular}{l|l}
\hline Criterios & \\
\hline $5^{\circ} \mathrm{C}$ & Altura (msnm) \\
\hline $2^{\circ} \mathrm{C}$ & $3300-3900$ \\
\hline $7^{\circ} \mathrm{C}$ & $3200-4100$ \\
\hline $2^{\circ} \mathrm{C}$ & $3100-3600$ \\
\hline $2^{\circ} \mathrm{C}$ & $4400-4900$ \\
\hline $4^{\circ} \mathrm{C}$ & 4300 \\
\hline $1^{\circ} \mathrm{C}$ & $4200-4900$ \\
\hline
\end{tabular}

Vegetación arbustiva de
hasta 3 m de altura y
vegetación herbácea
Bosques de 5 a 7 m que
crecen torcidos por el
clima. Crecen aislados de
la vegetación arbustiva y
herbácea en sitios de
menor viento
Bosques con doseles de
entre 15 y 20 m con
sotobosque denso de
herbáceas, epífitas y
briofitas

\begin{tabular}{l} 
Fisionomía \\
Cordillera \\
Occidental \\
Occidental \\
Occidental \\
Occidental \\
\hline Occidental \\
Occidental \\
\hline Occidental \\
\hline
\end{tabular}

andosoles (oscuros) con profundo horizonte A, rico en materia orgánica que alcanza los 60 kg de carbono por metro cuadrado; (e) Herbazal Húmedo Montano Alto Superior del Páramo donde sus principales especies son de los géneros Stipa, Senecio y Plantago; (f) Herbazal Húmedo Subnival del Páramo donde las especies más representativas son los pastos de tallo corto, rosetas y hierbas en cojín y arbustos como el Chuquiragua,

Astrágalo y Valeriana; (g) Herbazal Inundable del Páramo tiene una vegetación flotante con especies que forman cojines o parches aislados, este es un ecosistema azonal; (h) Herbazal Ultrahúmedo Subnival del Páramo presenta una vegetación arbustal y almohadillas dispersas tiene una importante presencia de briofitas y una alta diversidad de especies; (i) Herbazal y Arbustal Siempreverde Subival del Páramo presenta una vegetación herbazal con una mezcla de arbustos esclerófilos semipostrados con una altura de 0,5 a 1,5 metros. Se localiza en las cumbres más altas de la 
cordillera con congelamiento y descongelamiento del agua en el suelo en un mismo día, debido a ello las especies han sufrido adaptaciones fisiológicas singulares (Figura 4).

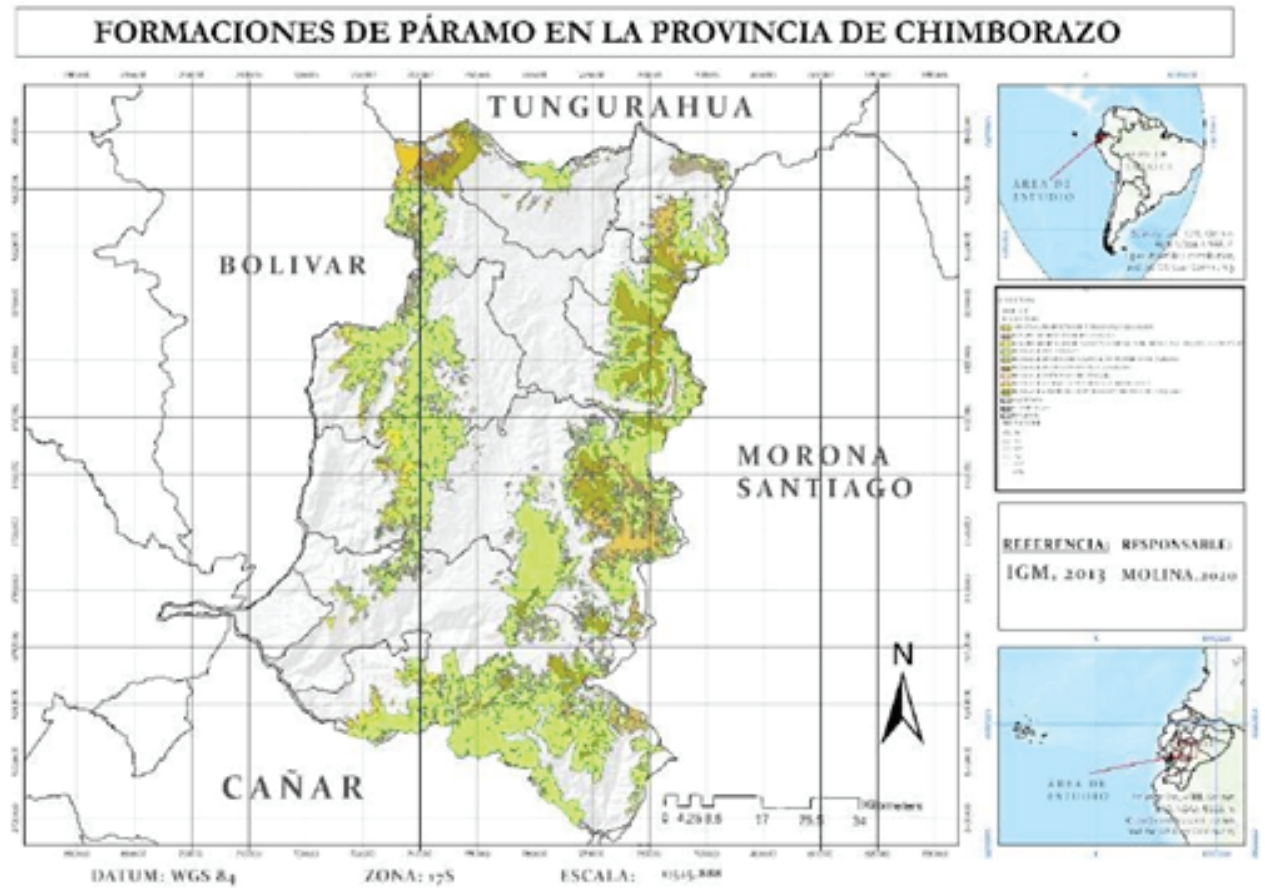

Figure 4

Ecosistema páramo de alto valor ecológico.

\subsubsection{Análisis}

Los ecosistemas de alto valor ecológico son aquellos que contienen uno o más de los atributos biológicos, sociales y culturales considerados de importancia crítica o excepcional para cierta área [44]. Los páramos son ecosistemas zonales ubicados principalmente en las montañas tropicales de Centro y Suramérica, aproximadamente entre 3000 y 4500 m.s.n.m. y conforman un piso altitudinal de las cordilleras de los trópicos [45]. Al ser el ecosistema páramo, un ecotopo exclusivo de los Andes Ecuatoriales Húmedos, estos espacios forman parte de la estructura montañosa andina y verticalmente representan los orobiomas terminales de dichas vertientes tropandinas y su objetivo es cumplir importantes funciones culturales y económicas las cuales dependen de las lógicas propias de las culturas de los grupos humanos que los habitan [46].

En este sentido en la provincia de Chimborazo, el ecosistema páramo se encuentra distribuido en distintas modalidades de conservación, una de estas son, las áreas protegidas, las mismas que son consideradas como una de las mejores estrategias 
de conservación de la diversidad biológica [47] y la integridad ecológica [48]; ya que son la base de todas las estrategias nacionales e internacionales de conservación porque cuentan con el apoyo del gobierno y tratados internacionales como el Convenio sobre la Diversidad Biológica y en efecto, son el núcleo de los esfuerzos por proteger especies amenazadas del mundo y cada vez juegan un papel importante no solo como proveedores esenciales de servicios ecosistémicos y recursos biológicos, sino como elementos fundamentales en las estrategias de mitigación al cambio climático [49]. Esto se puede evidenciar en la provincia de Chimborazo, por cuanto dentro del PANE se encuentran 92 455,91 ha que representan el 14,22\% de la provincia, lo cual resulta similar a otros estudios donde estos sitios representan el 15,93\% del área que están en alguna área protegida [50] y el 15\% de vegetación natural en sietes área protegidas [51]; sin embargo los programas de manejos individuales y colectivos permiten también regular el acceso a los recursos naturales [52].

La provincia de Chimborazo presenta 9 formaciones vegetales pertenecientes al ecosistema páramo que representan el $36,40 \%$ de la provincia de Chimborazo con un total de 234.830,52 ha, siendo la formación vegetal Herbazal del Páramo con un 25,66\% la predominante en la provincia y el de menor extensión es el Herbazal Inundable del Páramo, con un 0,11\% (Tabla 4).

\subsection{Representatividad del ecosistema páramo en las modalidades de conservación de la provincia}

El ecosistema páramo de alto valor ecológico de la provincia de Chimborazo se encuentra distribuido de la siguiente manera: (a) modalidad PANE representa el 7,95\% del total de las formaciones vegetales pertenecientes a los espacios naturales protegidos en relación con el total de hectáreas de las formaciones vegetales del ecosistema páramo en la provincia; (b) la modalidad Bosques y Vegetación Protectora representa el 3,13\% con relación al total de formaciones vegetales del ecosistema páramo en la provincia; y (c) la modalidad PSB Colectivo e Individual representa el 4,01\% del total de las formaciones vegetales pertenecientes a los espacios protegidos de la provincia (Figura 5). Finalmente, tan sólo el $15,10 \%$ de formaciones vegetales del ecosistema páramo de la provincia de Chimborazo se encuentran bajo modalidad de conservación.

\subsubsection{Representatividad especifica del ecosistema páramo en las difer- entes modalidades de conservación de la provincia de Chimbo- razo}

La formación vegetal (a) Arbustal Siempreverde y Herbazal del Páramos en la modalidad de conservación PANE existe el 4,86\% del total de hectáreas, en la modalidad de 


\section{Table 4}

Análisis de formaciones vegetales de páramo en la provincia.

\begin{tabular}{|c|c|c|c|}
\hline $\begin{array}{l}\text { Formaciones Vegetales } \\
\text { (páramo) }\end{array}$ & Hectáreas & $\begin{array}{l}\text { \% Provincia de } \\
\text { Chimborazo }\end{array}$ & Ubicación cantones \\
\hline $\begin{array}{l}\text { Arbustal siempreverde y } \\
\text { herbazal del Páramo }\end{array}$ & $24.609,95$ & $3,79 \%$ & $\begin{array}{l}\text { Guano, Riobamba, Penipe, } \\
\text { Guamote, Alausí, Chunchi, } \\
\text { Pallatanga y Colta }\end{array}$ \\
\hline $\begin{array}{l}\text { Bosque siempreverde del } \\
\text { Páramo }\end{array}$ & $2.165,24$ & $0,33 \%$ & Penipe \\
\hline $\begin{array}{l}\text { Bosque siempreverde } \\
\text { montano alto de la Cordillera } \\
\text { Occidental de los Andes }\end{array}$ & $10.420,11$ & $1,66 \%$ & $\begin{array}{l}\text { Colta, Pallatanga, Alausí, } \\
\text { Chunchi, Guano }\end{array}$ \\
\hline Herbazal del Páramo & $166.769,76$ & $25,66 \%$ & $\begin{array}{l}\text { Guano, Penipe, Chambo, } \\
\text { Riobamba, Colta, Pallatanga, } \\
\text { Guamote, Alausí, Chunchi }\end{array}$ \\
\hline $\begin{array}{l}\text { Herbazal húmedo montano } \\
\text { alto }\end{array}$ & $1.528,22$ & $0,24 \%$ & Guano, Colta, Riobamba, \\
\hline $\begin{array}{l}\text { superior del Páramo Herbazal } \\
\text { húmedo subnival }\end{array}$ & $1.820,13$ & $0,28 \%$ & Penipe Guano, Riobamba \\
\hline $\begin{array}{l}\text { Páramo Herbazal inundable } \\
\text { del Páramo }\end{array}$ & 80,43 & $0,11 \%$ & Chunchi \\
\hline $\begin{array}{l}\text { Herbazal ultrahúmedo } \\
\text { subnival }\end{array}$ & $3.481,42$ & $0,54 \%$ & Guano, Riobamba \\
\hline $\begin{array}{l}\text { del Páramo Herbazal y } \\
\text { Arbustal }\end{array}$ & $24.955,26$ & $3,84 \%$ & Guano, Penipe, Chambo, \\
\hline $\begin{array}{l}\text { siempreverde subnival del } \\
\text { Páramo }\end{array}$ & & & $\begin{array}{l}\text { Riobamba, Colta, Guamote, } \\
\text { Alausí y Chunchi }\end{array}$ \\
\hline Total & $234.830,52$ & 36,40 & \\
\hline
\end{tabular}

Bosques Protectores el 0,41\% del total de hectáreas y en el PSB Colectivo e Individual el 5,73\%; (b) Bosque Siempreverde del Páramo en la modalidad PANE, representa el 2,25\% del total de la provincia. Modalidad Bosques Protectores, representa el 1,28\% y modalidad PSB Colectivo e Individual representan el 0,24\%; (c) Bosque Siempreverde Montano Alto de la Cordillera Occidental de los Andes en la modalidad PANE no presenta dicha formación vegetal en la modalidad Bosques Protectores, representan el 2,98\% del total de la provincia y la modalidad PSB Colectivo e Individual, representan el 2,35\%; (d) Herbazal del Páramo en la modalidad PANE, representa el 5,27\% del total de la formación vegetal de la provincia, en la modalidad Bosques Protectores, representan el 3,45\% y en el PSB Colectivo e Individual representan el 1,84\%; (e) Herbazal Húmedo Montano Alto Superior del Páramo en la modalidad PANE, representa el $24,30 \%$ en la provincia en los Bosques protectores representan el 3.69\% y en la modalidad PSB Colectivo e Individual representan el 2,85\%; (f) Herbazal Húmedo Subnival del Páramo en la modalidad PANE representa el $43,60 \%$ del total de la formación de la provincia de Chimborazo y la modalidad PSB Colectivo e Individual con el 54,94\%; (g) Herbazal Ultrahúmedo Subnival del Páramo en la modalidad PANE representa el 53,76\% de la 


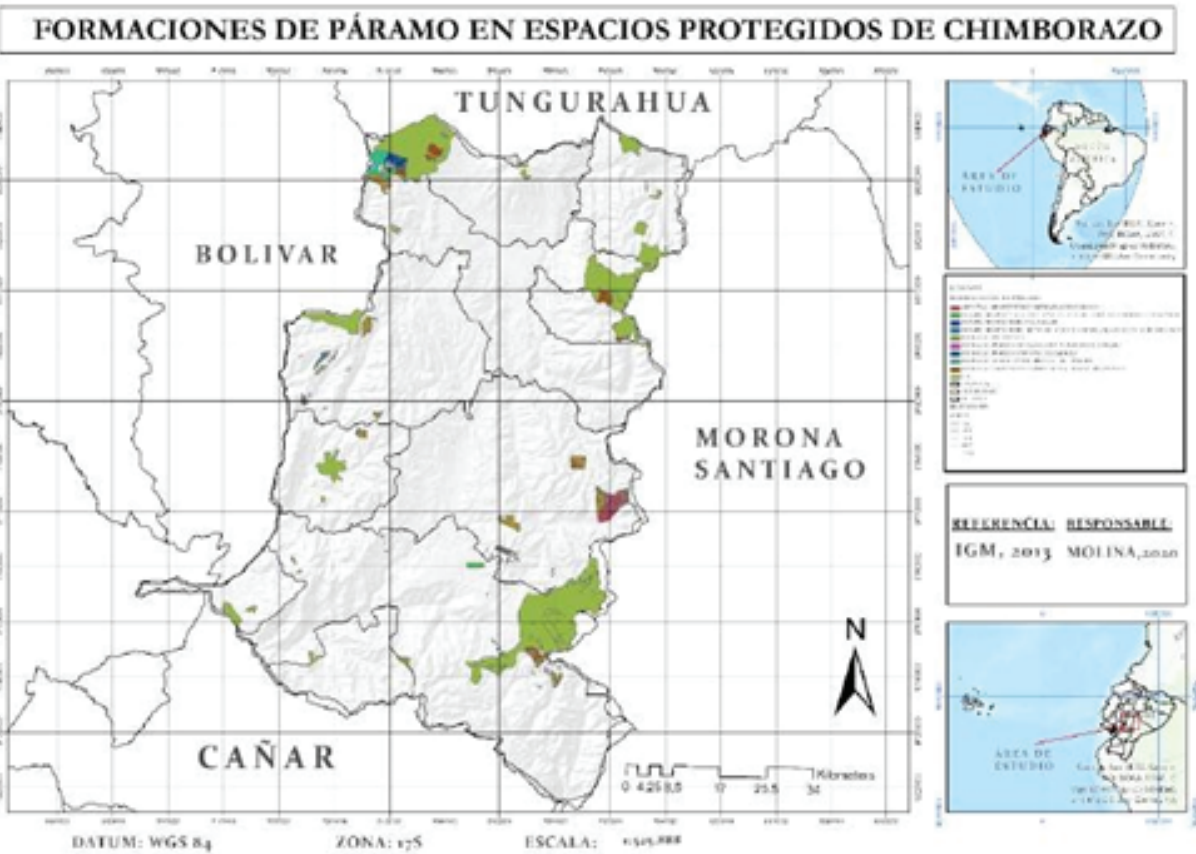

Figure 5

Representatividad del ecosistema páramo de alto valor ecológico en las AP'S de Chimborazo.

formación vegetal presente en la provincia y la modalidad PSB Colectivo e Individual representa el 26,45\%; (h) Herbazal y Arbustal Siempreverde Subnival del Páramo en la modalidad PANE representa el $22,78 \%$ del total de la formación de la provincia de Chimborazo, en la modalidad Bosques Protectores representa el 4,56\% de la formación de la provincia y en la modalidad PSB Colectivo e Individual representa el 11,14\% (Tabla 5).

La formación vegetal Herbazal del Páramo es la más representativa dentro de los espacios protegidas con el $2,71 \%$ de la provincia de Chimborazo, seguida de la formación Herbazal y Arbustal siempreverde subnival del Páramo con el 1,48\% de la provincia y la menos representativa es la Bosque siempreverde del Páramo que representa únicamente el 0,01\% de la provincia (Tabla 6).

\subsubsection{Análisis}

El ecosistema páramo representa el 36,9\% de toda la superficie de la provincia de Chimborazo y al igual que en otras regiones se caracterizan por presentar grandes áreas de gramíneas con presencia principalmente de Calamagostris [53], además que factores como la altitud, el clima contribuyen a que se desarrolle un tipo de vegetación muy particular que presenta un alto grado de endemismo [54]. Los suelos de los páramos son de origen volcánico, por cuanto el carbono está más concentrado debido a la baja temperatura y descomposición lenta de los residuos vegetales en este 
Table 5

Formaciones vegetales y Modalidades de conservación vs provincia de Chimborazo.

\begin{tabular}{|c|c|c|c|c|c|c|c|}
\hline \multirow{2}{*}{$\begin{array}{l}\text { Modalidades de } \\
\text { conservación }\end{array}$} & \multicolumn{2}{|l|}{ PANE } & \multicolumn{2}{|c|}{$\begin{array}{l}\text { Bosques } \\
\text { protectores }\end{array}$} & \multicolumn{2}{|c|}{$\begin{array}{l}\text { PSB colectivoe Indi- } \\
\text { vidual }\end{array}$} & \multirow{2}{*}{$\begin{array}{l}\text { Total de F.V } \\
\text { en modalidad } \\
\text { de } \\
\text { conservación }\end{array}$} \\
\hline & ha & $\begin{array}{l}\text { \%/F.V (P. } \\
\text { Chim } \\
\text { boraz o) }\end{array}$ & ha & $\begin{array}{l}\text { \%/F.V (P. } \\
\text { Chim } \\
\text { boraz o) }\end{array}$ & ha & $\begin{array}{l}\text { \%/F.V (P. } \\
\text { Chim } \\
\text { boraz o) }\end{array}$ & \\
\hline $\begin{array}{l}\text { Arbustal siempreverde } \\
\text { y herbazal del Páramo }\end{array}$ & $1.195,46$ & 4,86 & 101,16 & 0,41 & $1.408,99$ & 5,73 & $11 \%$ \\
\hline $\begin{array}{l}\text { Bosque siempreverde } \\
\text { del Páramo }\end{array}$ & 48,78 & 2,25 & 27,72 & 1,8 & 5,28 & 0,24 & $4,29 \%$ \\
\hline $\begin{array}{l}\text { Bosque siempreverde } \\
\text { montano alto de la } \\
\text { Cordillera Occidental } \\
\text { de los Andes }\end{array}$ & 0 & 0 & 310,78 & 2,98 & 244,51 & 2,35 & $5,33 \%$ \\
\hline Herbazal del Páramo & $8.787,36$ & 5,27 & $5.756,78$ & 3,45 & 3063,1 & 1,84 & $10,56 \%$ \\
\hline $\begin{array}{l}\text { Herbazal húmedo } \\
\text { montano alto superior } \\
\text { del Páramo }\end{array}$ & 371,42 & 24,3 & 56,33 & 3,69 & 43,61 & 2,85 & $30,84 \%$ \\
\hline $\begin{array}{l}\text { Herbazal húmedo } \\
\text { subnival Páramo }\end{array}$ & 793,69 & 43,63 & 0 & 0 & 1.000 & 54,94 & $98,57 \%$ \\
\hline $\begin{array}{l}\text { Herbazal ultrahúmedo } \\
\text { subnival del Páramo }\end{array}$ & $1.871,57$ & 53,76 & 0 & 0 & 920,7 & 26,45 & $80,21 \%$ \\
\hline $\begin{array}{l}\text { Herbazal y Arbustal } \\
\text { siempreverde subnival } \\
\text { del Páramo }\end{array}$ & $5.685,66$ & 22,78 & $1.137,12$ & 4,56 & 2780,17 & 11,14 & $38,48 \%$ \\
\hline $\begin{array}{l}\text { Total F.V bajo } \\
\text { modalidad de } \\
\text { conservación }\end{array}$ & $18.753,94$ & 7,95 & $7.389,89$ & 3,13 & $9.466,36$ & 4,01 & $\begin{array}{l}35.610,19 \text { ha } \\
(15,10 \%)\end{array}$ \\
\hline
\end{tabular}

ecosistema [55], es decir, el páramo puede brindar servicios ecosistémicos gracias sus características ecológicas especiales como se evidencia en varios estudios [56, 57].

En relación al total de las formaciones vegetales del ecosistema páramo pertenecientes a las modalidades de conservación vs total de las formaciones vegetales del ecosistema páramo pertenecientes a la provincia, se evidencian las siguientes cifras: (a) modalidad PANE representa el 7,95\%, en la modalidad Bosques y Vegetación Protectora representa el 3,13\% y en la modalidad PSB Colectivo e Individual representa el 4,01\% del total de las formaciones vegetales pertenecientes a los espacios protegidos de la provincia de Chimborazo en relación al total de formaciones vegetales presentes en la provincia.

Partiendo de las cifras anteriores se tiene que, el 15,10\% de formaciones vegetales del páramo en la provincia de Chimborazo se encuentran bajo modalidad de conservación; de tal modo que, la formación vegetal Herbazal del Páramo es la más representativa dentro de los espacios protegidos con el $2,71 \%$, la misma que como en el resto 
Table 6

Formaciones vegetales del páramo en modalidades de conservación con relación a la provincia de Chimborazo.

\begin{tabular}{|c|c|c|}
\hline $\begin{array}{l}\text { Formación vegetal en espacios } \\
\text { protegidos }\end{array}$ & $\begin{array}{l}\text { Hectáreas en espacios } \\
\text { protegidos }\end{array}$ & \% Provincia de Chimborazo \\
\hline $\begin{array}{l}\text { Arbustal siempreverde y herbazal } \\
\text { del Páramo }\end{array}$ & $2.705,61$ & $0,42 \%$ \\
\hline Bosque siempreverde del Páramo & 81,78 & $0,01 \%$ \\
\hline $\begin{array}{l}\text { Bosque siempreverde montano } \\
\text { alto de la Cordillera Occidental de } \\
\text { los Andes }\end{array}$ & 555,29 & $0,08 \%$ \\
\hline Herbazal del Páramo & $17.607,24$ & $2,71 \%$ \\
\hline $\begin{array}{l}\text { Herbazal húmedo montano alto } \\
\text { superior del Páramo }\end{array}$ & 471,36 & $0,07 \%$ \\
\hline $\begin{array}{l}\text { Herbazal húmedo subnival } \\
\text { Páramo }\end{array}$ & $1.793,69$ & $0,28 \%$ \\
\hline $\begin{array}{l}\text { Herbazal ultrahúmedo subnival } \\
\text { del Páramo }\end{array}$ & $2.792,27$ & $0,43 \%$ \\
\hline $\begin{array}{l}\text { Herbazal y Arbustal siempreverde } \\
\text { subnival del Páramo }\end{array}$ & $9.602,95$ & $1,48 \%$ \\
\hline
\end{tabular}

del país abarca la mayor extensión de los ecosistemas de montaña. Se caracteriza por tener suelos andosoles con un profundo horizonte $A$, rico en materia orgánica y contiene una gran cantidad de agua por unidad de volumen, por cuanto esta formación está caracterizado por tener una dominancia de los géneros Calamagrostis, Agrostis, Festuca, Cortaderia y Stipa [58].

Puntualmente dentro de la provincia, la formación Herbazal húmedo subnival Páramo se muestra como las más representativa ya que integra un área de 1.793,69 ha, esta formación se encuentra restringida a las partes más altas, generalmente sobre los 4500 m.s.n.m.; y dentro de esta formación se puede apreciar pastos de tallo corto, rosetas acaulescentes y hierbas en cojín. Sin embargo, en términos porcentuales estos han disminuido pasando de 18,04\% a 18,01\% [59], y aunque el análisis se realizó en el área del Chimborazo, es indudable que así como otros ecosistemas, este está sujeto a actividades que promueven su degradación.

Sin embargo, los esfuerzos no han sido suficientes, ya que muchas de estas áreas se encuentran en entornos transformados por espacios y prácticas de ocupación del territorio y aprovechamiento de los recursos naturales, tomando en cuenta que en contraste al $86 \%$ de conservación del bosque húmedo tropical, la conservación del ecosistema páramo con el $1 \%$, es nulo [60]; esta problemática se asemeja a lo que ocurre en la provincia de Tungurahua, puesto que aquí la intervención mosaico-agropecuario con respecto al año 2000 del ecosistema páramo más el glaciar ha incrementado en un $60 \%$, y los factores que propician esta degradación son aquellas que sobrepasan los 3600 msnm [61]. Esta problemática ocurre a pesar que los bosques húmedos 
amazónicos y los páramos húmedos son los que tienen una superficie mayor al 75\% [62], razón por la cual entre los primeros criterios de priorización para las modalidades de conservación están los boques nativos y los páramos [60, 63]. En este sentido entender la importancia del ecosistema páramo se convierte, por tanto, en un elemento fundamental para comprender, prever y minimizar los efectos negativos de la presión antrópica [64].

\subsubsection{Conclusiones}

La provincia de Chimborazo cuenta con 121 espacios protegidos que corresponden a 116 562,30 ha, que representan el 17,92\% de su territorio, los mismos que están divididos en 3 modalidades de conservación, que son el PANE con 92 455,91 ha que representan el 14,22\% de la provincia, los Bosques Protectores con 9 494,36 ha que representa el 1,46\% de la provincia y el Programa Socio Bosque (PSB) Colectivo e individual con 14 612,03 ha que representan el 2,25\% de la provincia. Estas modalidades están presentes en el $60 \%$ de los cantones de la provincia, y únicamente 3 espacios naturales protegidos cuentan con documentos de planificación para el manejo.

El ecosistema páramo representa el 36,40\% del territorio de la provincia de Chimborazo, con un total de 234830,52 ha y está conformado por 9 formaciones vegetales. Las formaciones con mayor extensión son el Herbazal de páramo con 166 769,76 ha que representan el $25,66 \%$ de la provincia, seguido de la formación vegetal Herbazal y arbustal siempreverde subnival del páramo con 24 955,26 ha que representa el $3,84 \%$ de la provincia, luego la formación vegetal Arbustal siempreverde y herbazal del Páramo con 24 609,95 ha que representa el 3,79\% de la provincia, y la formación vegetal con menor extensión es el Herbazal inundable del páramo con 80,43 ha que representa el $0,11 \%$ de la provincia.

El 15,10\% del ecosistema páramo se hallan bajo modalidad de conservación en la provincia de Chimborazo, siendo el PANE la modalidad de conservación que mayor cobertura de protección ofrece con 18 753,94 ha que representa el 7,95\% del total de la provincia, seguido esta la modalidad de Programa Socio Bosque (PSB) Colectivo e individual con 9 466,36 ha que representa el 4,01\% y al final los Bosques Protectores con 7389,89 ha que representa el 3,13\%. Sin embargo, el $84,90 \%$ del referido ecosistema se encuentran en entornos que han sido transformados para producir alimentos, forrajes, fibras y combustibles, a través de prácticas de uso de los suelos no sostenibles que, combinadas con el cambio climático, ponen en riesgo la disponibilidad de agua. 


\section{Agradecimientos}

A la Escuela Superior Politécnica de Chimborazo por brindar un espacio para generar contenidos técnicos que permitan contribuir al manejo y conservación de los recursos naturales.

\section{Conflictos de Interés}

No existen intereses particulares por parte de los autores, de la entidad científica o financiadora que pudiesen afectar directa o indirectamente a los resultados obtenidos.

\section{References}

[1] Llambi D, Cuesta F. La diversidad de los páramos andinos en el espacio y en el tiempo.. 2014 [cited 2020 Jun 18]. Available from: https://www.researchgate. net/publication/263279001_La_diversidad_de_los_paramos_andinos_en_el_ espacio_y_en_el_tiempo

[2] Castaño C. Colombia alto andina y la significancia ambiental del bioma páramo en el contexto de los andes tropicales: una aproximación a los efectos futuros por el cambio climático global (global climatic tensor). 2002;987.

[3] Avellaneda LM, León TE, Torres E. Impact of potato cultivation and cattle farming on physicochemical parameters and enzymatic activities of Neotropical high Andean Páramo ecosystem soils. Sci Total Environ. 2018;631-632:1600-10.

[4] Londoño C, Cleef A, Madriñán S. Angiosperm flora and biogeography of the páramo region of Colombia, Northern Andes. Flora - Morphol Distrib Funct Ecol Plants. 2014;209(2):81-7.

[5] Curiel Yuste J, Hereș A-M, Ojeda G et al. Soil heterotrophic CO2 emissions from tropical high-elevation ecosystems (Páramos) and their sensitivity to temperature and moisture fluctuations. Soil Biol Biochem. 2017;110:8-11.

[6] Hofstede R, Segarra P, Mena P. Los Páramos del Mundo. 2003. 290 p. Available from: http://www.portalces.org/sites/default/files/references/038_Hofstedeet ${ }^{\sim} a l$. $\{\%\} 28 e d s\{\%\} 29.2003 . L o s P a r a m o s d e l M u n d o . p d f$

[7] Morales J, Estévez J. El páramo: ¿Ecosistema en vía de extinción? Rev Luna Azul. 2006;22:39-51.

[8] Mena P, Medina G. La Biodiversidad de los Páramos en el Ecuador. Los páramos del Ecuador. 2001;23-48.

[9] García V, Márquez C, Isenhart T, Rodríguez M, Crespo S, Cifuentes A. Evaluating the conservation state of the páramo ecosystem: An object-based image analysis and CART algorithm approach for central Ecuador. Heliyon. 2019;5(10). 
[10] Mena P, Hofstede R. The ecuadorian páramos. Botánica económica los Andes Cent. 2006;91-109.

[11] Cuesta F, Bert D-B. Temperate Grasslands of South America. 2008;41.

[12] Álvarez CF, Clavijo A, Rojas H, Uribe S, Pyrcz TW, Marín MA. Aporte del área de influencia del páramo de Belmira (Santa Inés) a la diversidad regional de Pronophilina (Lepidoptera: Satyrinae) del norte de los Andes. Rev Mex Biodivers. 2017;88(2):4029.

[13] Villota A, León S, Behling H. Vegetation and environmental dynamics in the Páramo of Jimbura region in the southeastern Ecuadorian Andes during the late Quaternary. J South Am Earth Sci. 2012;40:85-93.

[14] Carrillo G, Silva B, Rollenbeck R, Célleri R, Bendix J. The breathing of the Andean highlands: Net ecosystem exchange and evapotranspiration over the páramo of southern Ecuador. Agric For Meteorol. 2019;265(October 2018):30-47.

[15] Serrano D, Galárraga R. El páramo andino: características territoriales y estado ambiental. Aportes interdisciplinarios para su conocimiento. Estud Geográficos. 2015;76(278):369-93.

[16] Evans NM. Ecosystem services: On idealization and understanding complexity. Ecol Econ. 2019;156:427-30.

[17] Corvalán C, Hales S, López Guarnido O. Ecosistemas y bienestar humano: síntesis sobre salud. Un Inf la Evaluación los Ecosistemas del Milen. 2005;10(ninguno):64.

[18] Vásquez C, Ariza A, Pinilla G. Descripción del estado trófico de diez humedales del altiplano cundiboyacense. 2009 p. 75.

[19] Evaluación de los Ecosistemas del Milenio. Los Ecosistemas y el bienestar humano: Humedales y agua, Informe de síntesis. $6^{\text {th }}$ ed. Washington, DC.: World Resources Institute; 2005.

[20] Van-der-Hammen T. Diagnóstico, cambio global y conservación. Вестник Казнму. 2002;987.

[21] Culhane F, Teixeira H, Nogueira AJA et al. Risk to the supply of ecosystem services across aquatic ecosystems. Sci Total Environ. 2019;660:611-21.

[22] Araújo CVM, Moreira M, Sousa JP, Ochoa V, Encalada AC, Ribeiro R. Contaminants as habitat disturbers: PAH-driven drift by Andean paramo stream insects. Ecotoxicol Environ Saf. 2014;108:89-94.

[23] Ramsay PM. Giant rosette plant morphology as an indicator of recent fire history in Andean páramo grasslands. Ecol Indic. 2014;45:37-44.

[24] Otero JD, Figueroa A, Muñoz FA, Peña MR. Loss of soil and nutrients by surface runoff in two agro-ecosystems within an Andean paramo area. Ecol Eng. 2011;37(12):203543. 
[25] Beltrán K, León S, Velástegui A. sistemas ecológicos y caracterización florística de los páramos en el Ecuador. 2009; Available from: http://biblio.flacsoandes.edu.ec/ catalog/resGet.php?resld=43577

[26] MAE. Sistema de clasificación de los ecosistemas del ecuador continental. Quito: Subsecretaría de Patrimonio Natural; 2013. Available from: http://app.sni.gob.ec/ sni-link/sni/PDOT/NIVELNACIONAL/MAE/ECOSISTEMAS/DOCUMENTOS/Sistema. pdf

[27] Bustamante M, Albán M, Argüello M. Los páramos de Chimborazo un estudio socioambiental para la toma de desiciones. Quito; 2011.

[28] Medina G, Hofstede R. Páramos del Ecuador: Partuicularidades, problemas y perspectivas. 2001; Available from: https://www.portalces.org/sites/default/ files/references/044_Menaet ${ }^{\sim}$ al.(Eds.).2001.ParamosEcuador.PORTADA\{\%\}2B_ \{\%]2BHOJA\{\%\}2BTECNICA\{\%\}2BY\{\%\}2BPRESENTACION.pdf

[29] García H. Valoración de los bienes y servicios ambientales provistos por el Páramo de Santurbán. 2013.

[30] Mena VP. Los páramos ecuatorianos: Paisajes diversos, frágiles y estratégicos. 2010;54:97-122.

[31] Camacho M. Los páramos ecuatorianos: caracterización y consideraciones para su conservación y aprovechamiento sostenible. Anales. 2013;372(1):77-92.

[32] Klinger W, Ramirez G, Lozano L, Vargas L. Caracterización ecológica y sociocultural del páramo de frontiono o del sol. 2012;1-103.

[33] Cáceres A. Determinación de la representatividad biológica de la ornitofauna en ecosistemas acuáticos y terrestres relacionados con un sector del rio salado, espinarcusco para los meses diciembre 2013 y agosto 2014". An Geogr. 2014;34(2):93.

[34] Arias E, Chacón O, Induni G et al. Identificación de vacíos en la representatividad de ecosistemas terrestres en el Sistema Nacional de Áreas Protegidas de Costa Rica. Recur Nat y Ambient. 2008;54:21-7.

[35] GADP Chimborazo. Plan de desarrollo y de ordenamiento territorial de Chimborazo. 2019.

[36] Santiago I. Fundamentos de ArcGIS. Primera parte. 2005;

[37] Instituto Ecuatoriano Forestal y de Áreas Naturales y Vida Silvestre. Plan de manejo estratégico del parque nacional sangay. 1998;(Octubre). Available from: https://maecanar.files.wordpress.com/2018/02/ plan-de-manejo-estratc3a9gico-parque-nacional-sangay.pdf

[38] Ministerio del Ambiente-PM-RPFCH. Actualización del plan de manejo de la reserva de producción de funa chimborazo. Riobamba:EcoCiencia;2014.

[39] Ministerio del Ambiente (PANE). Subsistema de áreas protegidas del Estado: Patrimonio de Áreas Protegidas Naturales del Estado - PANE. 2014;14. 
[40] Rojas J. El pago por servicios ambientales como alternativa para el uso sostenible de los servicios ecosistémicos de los páramos. Ambient y Sostenibilidad. 2013;1(1):57.

[41] Ministerio del Ambiente -MAE. Bosques protectores- humedales del Ecuador. Ministerio del Ambiente;2015

[42] Ministerio del Ambiente (PSB). Programa Socio Bosque. 2018.

[43] Senplades. Proyecto socio bosque. 2013;53:1689-1699.

[44] Pariona W, Rooij T, Siles T, Domic E. Guía práctica para la identificación de Bosques de Alto Valor de Conservación en el norte de La Paz. 2011;60.

[45] Díaz M, Navarrete J, Suárez T. Páramos: ecosistemas sensibles. Rev Ing. 2005;(22):64-75.

[46] Ministerio del Ambiente de Colombia. Programa para el Manejo Sostenible y Restauración de Ecosistemas de la Alta Montaña colombiana. 2002;

[47] SERNAP. Guía de Modalidades de Conservación de la Biodiversidad. 2013; p. 48.

[48] Robles B. Las unidades de manejo para la conservación de vida silvestre y el Corredor Biológico Mesoamericano México. BiodiversidadGobMx. 2009;129.

[49] Dudley N. Directrices para la aplicación de las categorías de gestión de áreas protegidas. 2008.

[50] Koleft P, Tambutti M, March I, Esquivel R, Cantú C, Noriega A. Estado de conservación y tendencias de cambio. Vol 2. 2009. Identificación de prioridades y análi- sis de vacíos y omisiones en la conservación de la biodiversidad de México, en Capital natural de México.

[51] Neri M, Bustamante A, Vargas S, Guerrero J. Representatividad ecológica de las áreas naturales protegidas del Estado de Puebla, México. Ecol Apl. 2015;14(2):8793.

[52] Álvarez P. El uso y la conservación de la biodiversidad en propiedades colectivas. Una propuesta de tipología sobre los niveles de gobernanza. Rev Mex Sociol. 2014;76(5):199-226.

[53] Castañeda A, Montes C. Carbono almacenado en páramo andino. Entramado. 2017;13(1):210-21.

[54] Podwojewski P, Poulenard J. los suelos de los páramos Los suelos de los páramos del Ecuador. 2000;(January 2000):1-75.

[55] Ayala L, Villa M, Aguirre Z, Aguirre N. Cuantificación del carbono en los páramos del Parque Nacional Yacuri, provincias de Loja y Zamora Chinchipe, Ecuador. Cedamaz. 2014;4(1):45-52.

[56] Torres AM, Peña EJ, Zuñiga O, Peña J. Evaluacio“N del impacto de actividades antropicas en el almacenamiento de carbono en biomasa vegetal en ecosistemas de alta montaña de colombia. Boletín científico Cent Museos Mus Hist Nat. 2012;16(1):132-42. 
[57] Suárez D, Acurio C, Chimbolema S, Aguirre X. Análisis del carbono secuestrado en humedales Altoandinos de dos áreas protegidas del Ecuador. Ecol Apl. 2016;15(2):171-7.

[58] Ministerio del Ambiente-SNI. Sistema de clasificación de ecosistemas del Ecuador contnental. 2014.1-5.

[59] Paula PA, Zambrano L, Paula P. Análisis Multitemporal de los cambios de la vegetación, en la Reserva de Producción de Fauna Chimborazo como consecuencia del cambio climático. Enfoque UTE. 2018;9(2):125-37.

[60] MAE-Socio bosque. INCENTIVOS SOCIO BOSQUE Patrimonio. 2015; Available from: https://earthinnovation.org/wp-content/uploads/2014/09/ 05-Socio-Bosque-Ecuador.pdf

[61] Geoinformática y Sistemas Cia. Ltda. Estudio del Estado Actual del Ecosistema Páramo en Tungurahua", Honorable Gobierno Provincial de Tungurahua (HGPT) Deutsche Gesellschaft für Internationale Zusammenarbeit (GIZ) GmbH (Cooperación Alemana para el Desarrollo). 2015. 239.

[62] CISMIL, FLACSO S. II Informe Nacional de los Objetivos de Desarrollo del Milenio (ODM)- Alianzas para el desarrollo. Quito;2007.

[63] Granda M, Yánez P. Estudio sobre la precepción de los beneficios de programa socio bosque en la región Amazónica Ecuatoriana. 2017;26(2):28-37.

[64] Hofstede R, Calles J, López V et al. Los páramos Andinos ¿Qué Sabemos? Estado de conocimiento sobre el impacto del cambio climático en el ecosistema páramo. Quito;UICN:2014. 